\title{
Serotonergic modulation of the P300 event related brain potential
}

Michel Hansenne*, William Pitchot, Patrick Papart and Marc Ansseau

* Psychiatric Unit, Centre Hospitalier Universitaire du Sart Tilman (B-35), B-4000 Liège, Belgium

KEYWORDS: P300, neurobiology, serotonin, flesinoxan test, cognition

\section{ABSTRACT}

While dopaminergic, noradrenergic, cholinergic and gabaergic effects on the P300 component of the human event-related brain potential have been largely described, little is known about serotonergic influence. Therefore, we investigated the relationship between P300 and serotonergic activity as reflected by prolactin (PRL) response to flesinoxan, a 5-HT1A full agonist, among 28 normal subjects. Results showed a significant negative correlation between P300 amplitude and PRL response to flesinoxan ( $r=-0.47, p=0.01$ at Cz; $r=-0.45, p=0.01$ at $\mathrm{Pz}$ ). In contrast, both $\mathrm{P} 300$ latency and reaction time were not related to endocrine response. This study supports a role for serotonin in the neurobiological modulation of P300 amplitude. Clinical implications of these results are considered. 


\section{Introduction}

The P300 component of the event-related potential (ERP) is a positive deflection which occurs when a subject detects an informative task-relevant stimulus, and it is particularly interesting to the study of cognitive processes in normal subjects and in psychopathology (Donchin and Coles, 1988; Picton, 1992). P300 reflects memory updating (Donchin and Coles, 1988), or context closure (Verleger, 1988), and perhaps represents the transfer of relevant information to consciousness (Picton, 1992). P300 amplitude is related to stimulus probability, stimulus significance, task difficulty, motivation, vigilance (Johnson, 1986; Sommer and Matt, 1990), and P300 latency is mainly influenced by task complexity, but not response difficulty (McCarthy and Donchin, 1981; Smulders et al., 1995), and reflects the stimulus time evaluation (Kutas et al., 1977).

The identification of the brain structures and neurotransmitters responsible for the generation and/or modulation of P300 will contribute to a clearer understanding of its functional significance. In this context, psychopharmacological studies have provided some interesting insights into the underlying neurobiological substrate of P300. Cholinergic effects on P300 amplitude and latency have been largely described, with a decrease of P300 amplitude and increased latency after injection of an anticholinergic agent (i.e. scopolamine) and the opposite results with cholinergic drugs (i.e. physostigmine) (Hammond et al., 1987; Meador et al., 1989; Meador, 1995). The influences of noradrenergic, dopaminergic and gabaergic systems have been reported in many studies (Jonkman et al., 1997; Swick et al., 1994; Semlitsch et al., 1995; Hansenne et al., 1995). Clonidine (an alpha-2-noradrenergic agonist) decreases P300-like potential in monkey (Swick et al., 1994), and methylphenidate dopaminergic agonist enhances P300 amplitude in attention-deficit hyperactivity disorder children (Jonkman et al., 1997). Moreover, the benzodiazepine alprazolam reduces P300 amplitude in normal subjects (Semlitsch et al., 1995).

However, few data are available about the serotonergic modulation of P300 amplitude and latency. Pritchard et al. (1986) found no significant effect of fenfluramine serotonergic antagonist on P300 component. Meador et al. (1989) reported no significant influence of the antiserotonergic agent methysergide on P300. However, Ito et al. (1990) have demonstrated a significant relationship between P300 amplitude and the cerebrospinal fluid (CSF) concentration of the serotonin metabolite 5-hydroxyindoleacetic acid (5-HIAA) in demented patients. Moreover, recent studies have reported synergistic effects of combined antiserotonergic (i.e. fenfluramine) and anticholinergic (i.e. scopolamine) agents on P300 latency (Meador, 1995).

Neuroendocrine strategy may provide an indirect index of central neurotransmission. Recently, our group have developed a serotonergic challenge test using flesinoxan (Pitchot et al., 1995; Hansenne $F$, 1997). Flesinoxan is a highly potent and selective 5-HT1A agonist inducing a significant and dose-dependent release of prolactin (PRL) in normal subjects.

The aim of the present study was to investigate the relationship between serotonergic activity and P300. More precisely, we assessed the relationship between the P300 component and the 5HT1A activity reflected by the PRL response to flesinoxan challenge test in normal subjects. 


\section{Methods}

The study was conducted in 28 normal subjects who were not familiar with psychophysiological methods. The sample comprised 11 men and 17 women with a mean age of 39.2 years (SD = 9.8). The subjects were free of medical illness, as evidenced by clinical examination, past history and electrocardiogram (ECG). The protocol was approved by the Ethical Committee of the University of Liège Medical School and all subjects gave their informed consent.

The P300 event-related potential recording was performed in a sound-attenuated room. The subjects were tested until a total of 150 trials were obtained, after rejecting trials for eye movement or other artifact. The auditory stimuli were presented binaurally in a random serie at the rate of one trial every second. The frequent stimuli were tones of $1470 \mathrm{~Hz}, 70 \mathrm{~dB}$ and $40 \mathrm{~ms}$ duration, and the other 20 per cent (target) were tones of $1000 \mathrm{~Hz}, 70 \mathrm{~dB}$ and $40 \mathrm{~ms}$ duration. The subjects were asked to press a button for the rare stimuli. P300 amplitude and latency were measured as the difference in voltage between baseline and the higher point between 280 and $450 \mathrm{~ms}$ after the stimulus. P300 trials contaminated by blinks or large amplitude eye movements were automatically excluded by using a $50 \mu \mathrm{V}$ rejection criterion. Analysis of N100, P200 and N200 components will be reported elsewhere.

The EEG was recording using silver-silver chloride electrodes attached at $\mathrm{Cz}$ and $\mathrm{Pz}$ using linked earlobes for reference and right forehead for ground. All sites were cleaned with acetone and abraded to maintain a resistance below $5 \mathrm{k} \Omega$. EOG was recorded from above the left eye. Amplifier gains were set at 10000 , with a band pass of $0.05-35 \mathrm{~Hz}$, and digitized at $250 \mathrm{sample} / \mathrm{s}$ for $900 \mathrm{~ms}$ epochs (of which the first $200 \mathrm{~ms}$ were presentation activity).

The flesinoxan challenge test was performed in the same week as the P300 recording. An indwelling catheter was inserted into a subject's forearm vein at 08:30. Blood samples of $10 \mathrm{ml}$ were collected $30 \mathrm{~min}$ before and immediately before the injection of flesinoxan at 09:30. Successive blood samples were collected 15, 30, 60, 90 and $120 \mathrm{~min}$ after the injection. Flesinoxan (1 mg/70 kg body weight), diluted in saline solution to obtain $20 \mathrm{ml}$, was injected intravenously over $10 \mathrm{~min}$. Blood samples were centrifuged within $2 \mathrm{~h}$ and serum immediately frozen and kept at $-18^{\circ} \mathrm{C}$ until analysis.

PRL was measured by radioimmunoassay (RIA) with intra- and inter-assay coefficients of variation of $10.0 \pm 10.0$ per cent and a detection limit of $10 \mathrm{mIU} / \mathrm{ml}$. Hormonal response following flesinoxan was assessed by peak values following the injection, as well as by the area under the curve situated between the injection and the last blood sample. Analyses were performed using relative (delta) PRL values. Since the correlations between peaks and area under the curve relative values were very high $(r=0.91)$, only the peak relative (delta) values will be reported here.

The relationship between PRL values and the psychophysiological data were assessed by Pearson Product-Moment correlation coefficients, and performed using Statistica (4.5) for Windows (Statsoft Inc, 1993). 


\section{Results}

The mean P300 amplitude was $10.2 \mu \mathrm{V}$ at $\mathrm{Cz}$ and $10.1 \mu \mathrm{V}$ at $\mathrm{Pz}$ with values between 2.1 and 18.4 at $\mathrm{Cz}$ and between 2.5 and 15.4 at Pz. Mean P300 latency was $324 \mathrm{~ms}$ at $\mathrm{Cz}(\mathrm{SD}=18.4$ ), and 323 $\mathrm{ms}$ at $\mathrm{Pz}(\mathrm{SD}=18.7)$. The reaction time (RT) ranged from 203 to $367 \mathrm{~ms}$ with a mean of 284 . PRL response to flesinoxan ranged from 20 to 2396 with a mean of $550 \mathrm{mIU} / \mathrm{ml}(\mathrm{SD}=579.5)$.

Significant negative relationships were found between P300 amplitude and PRL values ( $r=$ 0.47, $p=0.01$ at $\mathrm{Cz} ; r=-0.45, p=0.01$ at $\mathrm{Pz}$ ) (Figure 1). In contrast, the relationships between PRL values and both P300 latency $(r=0.14$ at $\mathrm{Cz}$ and $r=0.21$ at Pz) and RT $(r=0.26)$ were not statistically significant.

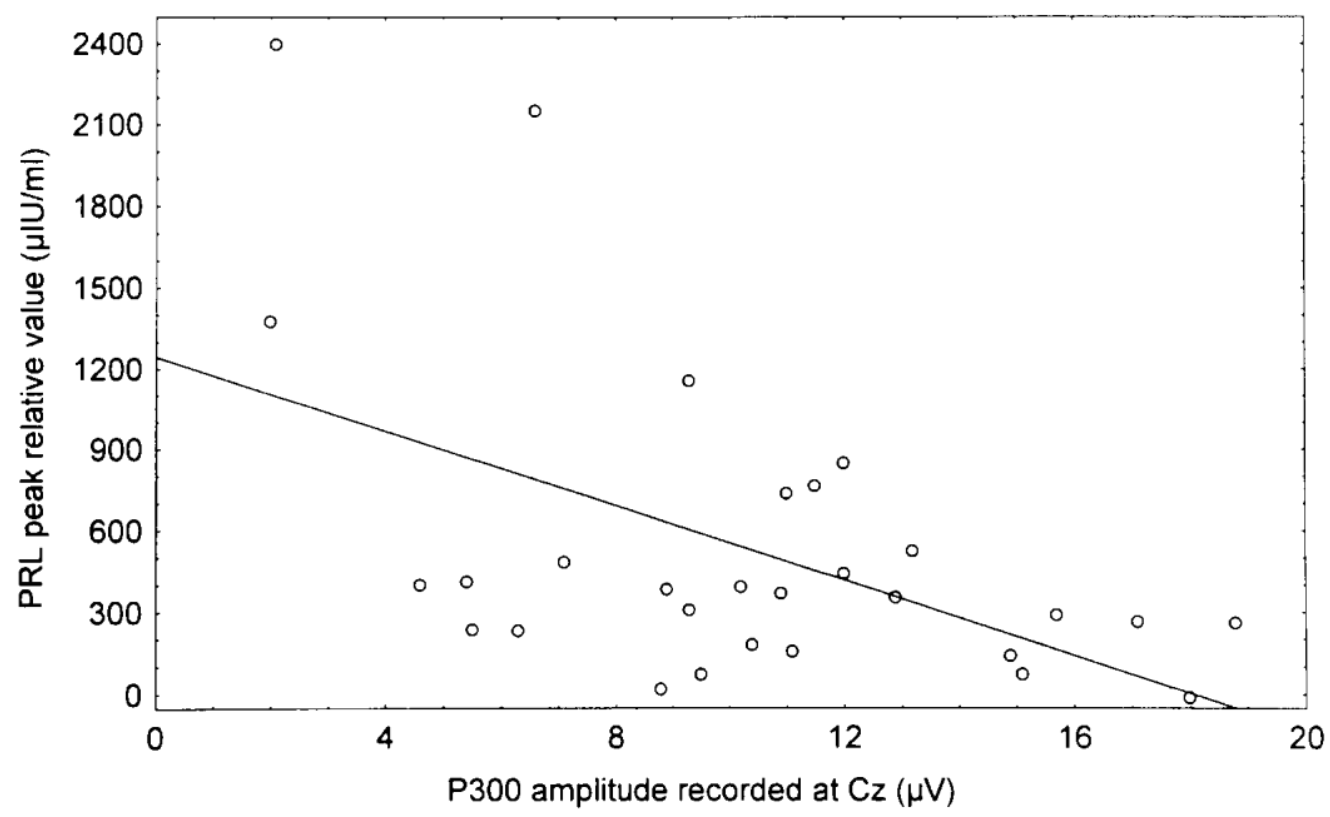

Figure 1. Relationship between P300 amplitude recorded at Cz and PRL response to flesinoxan among 28 normal subjects $(r=0.47, p=0.01)$

\section{Discussion}

By using a neuroendocrine challenge test with flesinoxan, we found a negative association between the serotonergic activity and P300 amplitude in normal subjects. Since flesinoxan stimulates very selectively post-synaptic 5HT1A receptors, our results indicate that P300 amplitude could be modulated by the sensitivity of 5-HT1A receptors at the post-synaptic level. The lack of relationship between PRL response to flesinoxan and both P300 latency and reaction time could suggest that the serotonergic system does not play a major role in stimulus time evaluation nor in motor response selection.

The implication of the serotonergic system in the generation and/or modulation of P300 amplitude has not been well documented. In contrast to our results, a positive relationship has been reported between P300 amplitude and the CSF concentration of the serotonin metabolite 5-hydroxyindoleacetic acid (5-HIAA) in demented patients (Ito et al., 1990). The opposite 
results of these two studies could be explained by different reasons. First, our flesinoxan challenge test assesses exclusively the sensitivity of 5-HT1A receptors, and not whole serotonergic activity as reflected by the CSF concentration of 5-HIAA. Second, the subjects differed between the two studies (normal versus demented patients), and many studies have reported an altered P300 amplitude and latency in dementia (Polich, 1991). Finally, the experimental paradigms were different: reaction time in the present study versus count in (Ito et al., 1990).

In the present study, a decrease of serotonergic function is associated with a high P300 amplitude. In fact, from a clinical point of view, high P300 amplitude has been described in antisocial impulsive behavior (Raine and Venables, 1988), and several lines of evidence have suggested an association between low serotonergic activity (and possibly 5-HT1A function) and impulsivity (New et al., 1997; Cocarro et al., 1989, 1990). Thus, a clinical interest of the present results is a possible link between P300 amplitude and impulsivity. Concerning depressive disorder, another indirect implication of the results is in identifying a subgroup of patients characterized by a high P300 amplitude and to treating them preferentially with drugs which act on 5-HT system. Finally, since P300 amplitude reflects memory updating (Donchin and Coles, 1988), these results support an implication of serotonin in cognitive processes like memory.

The lack of relationship between P300 latency and serotonergic activity is surprising, since the influences of serotonin on cognition have been reported in many studies (Cassel and Jeltsch, 1995; Harder et al., 1996; Buhot, 1997), and that P300 latency is delayed in high cognitive demand tasks and in aging and dementia (Picton, 1992; Polich, 1991). Again, the lack of an association between reaction time and serotonergic activity is surprising since recent results have suggested that serotonin reuptake inhibitor drugs shortens reaction time in healthy volunteers (Hasbroucq et al., 1997). However, the simplicity of the protocol used in the present study could be responsible for the negative results.

An important limitation of the present study is the selective effect of flesinoxan on the 5-HT1A receptors. Indeed, the pharmacologically-induced PRL response to flesinoxan is an indirect index of serotonergic neurotransmission and could involve areas of the brain having nothing to do with the generation of P300. However, the neuroendocrine effects induced by flesinoxan challenge are centrally mediated via 5-HT1A receptors that are found on cell bodies and dendrites of serotonergic neurons in the raphe nuclei (somatodendritic autoreceptors) and also in many brain areas where they occur as postsynaptic receptors (Groenink and Olivier, 1998). On the other hand, anatomical studies have provided some evidence about the existence of multiple P300 generators, including medial temporal lobe, frontal lobes, locus coeruleus, thalamus and parieto-temporal junction (Johnson, 1993).

In conclusion, this study supports a role for serotonin in the neurobiological modulation of P300 amplitude. However, for a more definitive answer on the precise role of serotonergic neurotransmission on P300, future studies should be conducted using agonist and antagonist serotonergic agents. 


\section{References}

Buhot, M. C. (1997). Serotonin receptors in cognitive behaviors. Current Opinion in Neurobiology, 7, 243 254.

Cassel, J. C. and Jeltsch, H. (1995). Serotonergic modulation of cholinergic function in the central nervous system: cognitive implications. Neuroscience, 69, 1-41.

Coccaro, E. F., Gabriel, S. and Siever, L. J. (1990). Buspirone challenge: preliminary evidence for a role for central 5-HT1A receptor function in impulsive aggressive behavior in human. Psychopharmacological Bulletin, 26, 393-405.

Coccaro, E., Siever, L. S., Klar, H. M., Maurer, G., Cochran, K., Cooper, T. B., Mohs, R. C. and Davis, K. L. (1989). Serotonergic studies in patients with affective and personality disorders: correlates with suicidal and impulsive aggressive behavior. Archives of General Psychiatry, 46, 587-599.

Donchin, E. and Coles, M. H. G. (1988). Is the P300 component a manifestation of context updating? Brain and Behavioral Science, 11, 357-374.

Groenink, L. and Olivier, B. (1998). Neuroendocrine effects induced by 5-HT1A receptor agonists are mediated centrally, via postsynaptic 5-HT1A receptors. Brain Research, in press.

Hammond, E. J., Meador, K. J., Aung-Din, R. and Wilder, B. K. (1987). Role of the cholinergic system in the generation of human cognitive evoked potentials. Neurology, 37, 346-350.

Hansenne, M., Pitchot, W., Gonzalez Moreno, A., Papart, P., Timsit-Berthier, M. and Ansseau, M. (1995). Catecholaminergic function and P300 amplitude in major depressive disorder (P300 and catecholamines). Electroencephalography and Clinical Neurophysiology, 96, 194-196.

Hansenne, M., Pitchot, W., Gonzalez Moreno, A., Papart, P., Reggers, J., Machurot, P.-Y. and Ansseau, M. (1997). Harm avoidance dimension of the tridimensional personality questionnaire and serotonin-1A activity in depressed patients. Biological Psychiatry, 42, 659-661.

Harder, J. A., Maclean, C. J., Alder, J. T., Francis, P. T. and Ridley, R. M. (1996). The 5-HT1A antagonist, WAY 100635, ameliorates the cognitive impairment induced by fornix transection in the marmoset. Psychopharmacology, 127, 245-254.

Hasbroucq, T., Rihet, P., Blin, O. and Possamai, C. A. (1997). Serotonin and human information processing: fluvoxamine can improve reaction time performance. Neuroscience Letters, 229, 204-208.

Ito, J., Yamoa, S., Fukuda, H., Mimori, Y. and Nakamura, S. (1990). The P300 event-related potentials in dementia of the Alzheimer type. Correlations between P300 and monoamine metabolites. Electroencephalography and Clinical Neurophysiology, 77, 174-178.

Johnson, R., Jr. (1986). A triarchic model of P300 amplitude. Psychophysiology, 23, 367-384.

Johnson, R., Jr. (1993). On the neural generators of the P300 component of the event-related potential. Psychophysiology, 30, 90-97.

Jonkman, L. M., Kemmer, C., Vertaben, M. N., Koelega, H. S., Camfferman, G., Van der Gaag, R-J., Buitelaar, J. K. and Van Engeland, H. (1997). Effects of methylphenidate on event-related potentials and performance of attention-deficit hyperactivity disorder children in auditory and visual selective attention tasks. Biological Psychiatry, 41, 690-702.

Kutas, M., McCarthy, G. and Donchin, E. (1977). Augmenting mental chronometry: the P300 as a measure of stimulus evaluation time. Science, 197, 792-795. 
McCarthy, G. and Donchin, E. (1981). A metric for thought: a comparison of P300 latency and reaction time. Science, 211, 77-80.

Meador, K. J. (1995). Cholinergic, serotonergic, and gabaergic effects on the ERP. In Karmos, G., Molnár, M., Csépe, V., Czigler, I. and Desmedt, J. E. (Eds), Perspectives of event-related potentials research, Electroencephalography and Clinical Neurophysiology, Suppl. 44, 151-155.

Meador, K. J., Loring, D. W., Davis, H. C., Setli, K. D., Patel, B. R. and Adams, R. J. (1989). Cholinergic and serotonergic effects on P3 potential and recent memory. Journal of Clinical and Experimental Neuropsychology, 11, 252-260.

New, A. S., Tresman, R. L., Mitropoulou, V., Benishay, D. S., Coccaro, E. F., Silverman, J. and Siever, L. J. (1997). Serotonin function and self-injurious behavior in personality disorder patients. Psychiatry Research, 69, 17-26.

Picton, T. W. (1992). The P300 wave of the human event-related potential. Journal of Clinical Neurophysiology, 9, 456-479.

Pitchot, W., Ansseau, M., Gonzalez Moreno, A., Lembreghts, M., Hansenne, M., Wauthy, J., Reel, C., Jammaer, R., Papart, P., Sulon, J. and Legros, J-J. (1995). The flesinoxan 5-HT1A receptor challenge test in major depression and suicidal behavior. Pharmacopsychiatry, 28, 91-92.

Polich, J. (1991). P300 in the evaluation of aging and dementia. In Brunia, C. H. M., Mulder, G. and Vertaben, M. N. (Eds), Event-related brain research, Electroencepholagraphy and Clinical Neurophysiology, Suppl. 42, 304-323.

Pritchard, W. S., Raz, N. and August, G. J. (1986). Brief report: No effect of chronic fenfluramine on the P300 component of the event-related potential. International Journal of Neuroscience, 35, 105-110.

Raine, A. and Venables, P. H. (1988). Enhanced P3 evoked potentials and longer recovery times in psychopaths. Psychophysiology, 25, 30-38.

Semlitsch, H. V., Anderer, P. and Saletu, B. (1995). Acute effects of the anxiolytics suriclone and alprazolam on cognitive processing utilizing topographic mapping of event-related brain potentials (P300) in healthy subjects. European Journal of Clinical Pharmacology, 49, 183-191.

Smulders, F. T. Y., Kok, A., Kenemans, J. L. and Bashore, T. R. (1995). The temporal selectivity of additive factor effects on the reaction process revealed in ERP component latencies. Acta Psychologica, 90, 97-109.

Sommer, W. and Matt, J. (1990). Awareness of P300-related cognitive processes: a signal detection approach. Psychophysiology, 27, 575-585.

Swick, D., Pineda, A. and Foote, S. L. (1994). Effects of systematic clonidine on auditory event-related potentials in squirrel monkeys. Brain Research Bulletin, 33, 79-86.

Verleger, R. (1988). Event-related potentials and cognition: a critique of the context updating hypothesis and an alternative interpretation of P3. Behavioral and Brain Sciences, 11, 343-356. 